\title{
Spider Neurotoxins as Modulators of NMDA Receptor Signaling
}

\author{
Artur Pałasz $^{1}$ (D) Marek Krzystanek ${ }^{2}$ (])
}

Received: 23 July 2021 / Accepted: 14 September 2021 / Published online: 25 September 2021

(C) The Author(s) 2021

\begin{abstract}
Molecules that selectively act on N-methyl-D-aspartate (NMDA) receptors may have a multidirectional effect by modulating the activity of NMDARs, affecting their active sites as well as by changing the composition of their subunits. The results of the clinical trials conducted so far in mood disorders and schizophrenia indicate that such agents may become new effective drugs for the treatment of these diseases. Number of spider neurotoxins e.g. ctenitoxins extracted from Phoneutria sp. venom act as potent and selective NMDAR blockers that do not disturb cortical and hippocampal glutamate signaling, LTP generation and synaptic neurochemistry. Possibly this intriguing kind of promising neuroregulatory peptides and polyamines can be clinically applicable in a wide spectrum of neuropsychiatric disorders, including epilepsy, neurotrauma and ischemic injuries. These novel medications can potentially be helpful in the future treatment of stroke and several neurodegenerative diseases.
\end{abstract}

Keywords NMDA $\cdot$ Neurotoxins $\cdot$ Ctenitoxin $\cdot$ Argiotoxin $\cdot$ Phoneutria

\section{Introduction}

Glutamate neurotransmission plays pivotal role in the integration and execution of higher mental functions of the brain being critically involved in the molecular mechanisms of memory, learning, consciousness and emotions (Dubois \& Liu, 2021; Krzystanek \& Pałasz, 2019). Among several known glutamate receptors, the ionotropic N-methylD-aspartate receptor (NMDAR) is considered to hold a dominant position in the generation of synaptic plasticity and hippocampal long-term potentiation (LTP). Unlike metabotropic G-coupled glutamate receptors transmembrane NMDAR molecule is a heterotetramer that consists of two obligatory GluN1 subunits and two GluN2 subunits of the same of different subtypes (GluN2A and GluN2B). GluN2 subunit may be also replaced by NR3. Glycine and glutamate binding sites are located in the homologous domains of GluN1 and GluN2A/B subunits, respectively. Several

Artur Pałasz

apalasz@sum.edu.pl

1 Department of Histology, Faculty of Medical Sciences, Medical University of Silesia, ul. Medyków 18, 40-752, Katowice, Poland

2 Department of Psychiatry and Psychotherapy, Clinic of Psychiatric Rehabilitation, Faculty of Medical Sciences in Katowice, Medical University of Silesia, ul. Ziolowa 45/47, 40-635 Katowice, Poland isoforms of GluN1 and at least four classes of GluN2 subunit (A-D) are currently known. The GluN1 subunit does exhibit distinct expression in majority of brain structures Psychopharmacomodulation of NMDARs is determined mainly by GluN2 subunits and their diverse isoforms may differentially affect receptor action. NMDAR activation requires uniquely simultaneous glutamate binding to GluN2 subunit, postsynaptic membrane depolarization to remove magnesium ions from the channel pore and glycine or D-serine binding to GluN1. The opening of nonselective cation channel enables sodium and calcium ions influx to neuroplasm that triggers activation of adenylate cyclase, $\mathrm{Ca}^{2+}$ and calmodulindependent protein kinase II (CaMKII). Several regulatory domains of the GluN2 subunit can bind a lot of diverse endo- and exogenous factors, including drugs and toxins e.g., polyamines, protons, zinc ions, glutathione, neurosteroids, ifenprodil, eliprodil, or even haloperidol. A common property of all NMDARs is binding several, psychomimetic open channel blockers (OCB) - ketamine, esketamine, phencyclidine (PCP), and dizocilpine (Regan et al., 2015).

Experimental and clinical studies indicate that substances that modulate NMDA receptor activity may be effective in the treatment of psychiatric diseases such as recurrent depression, bipolar depression and schizophrenic disorders. For this reason, it was decided to describe spider venomderived NMDA receptor modulators as novel, intriguing and 
so far understudied agents with a putative pharmacological potential.

\section{Pharmacomodulation of NMDARs Function in Neuropsychiatry}

Glutamate-mediated neuroplasticity plays an important role in the pathophysiology of mental disorders. NMDARs have been shown to be targets in the treatment of depressive, bipolar and schizophrenic disorders. It has been known for many years that ketamine, by blocking at the phencyclidine site within the NMDAR ion channel, rapidly improves depressive symptoms in bipolar depression (Zarate et al., 2012) as well as in the treatment of resistant bipolar depression (Diazgranados et al., 2010). Importantly, NMDAR antagonists may also reduce the number and severity of suicidal ideation in depression (Price et al., 2014). For this reason, new non-ketamine NMDAR antagonists are being searched and tested, which may become new drugs for the treatment of depressive disorders in the future (Kishimoto et al., 2016).

Contrary to the beneficial effects of NMDAR antagonists in depressive syndrome, they exert a psychodysleptic effect in schizophrenia. Therefore, in the treatment of schizophrenic disorders, substances are sought that modulate the activity of NMDARs by increasing its activity. Such NMDA receptor-enhancing agents in schizophrenia may be effective in improving common symptoms of disease, including cognitive impairment (Chang et al., 2019). Examples of such agents are $\mathrm{N}$-methyl-glycine (sarcosine) and memantine-both substances by modulating NMDA receptor activity can improve the activity of NMDARs in schizophrenia and reduce schizophrenic symptoms (Andrade 2017, Chang et al., 2019, Marchi et al., 2021). Although the previous studies and meta-analyzes do not confirm the significant effectiveness of substances increasing the activity of NMDARs on cognitive disorders in schizophrenia (apart from $\mathrm{N}$-acetyl cysteine), they indicate the direction of searching for new drugs to improve the effectiveness of schizophrenia pharmacotherapy (Marchi et al., 2021, Andrad, 2017, Chang et al., 2019).

Novel drugs for the treatment of schizophrenia symptoms and mood disorders may act not only on the ligand binding sites on the NMDAR, but may also alter the composition of the NMDAR subunits and thus modulate its activity. It was recently proven that antipsychotic drugs decrease the activity of NMDARs by reducing the number of GluN2B subunits in the receptor molecule (Krzystanek \& Pałasz, 2019). This indicates the possibility of a multidirectional pharmacological effect on the activity and composition of NMDAR, which may be used in the development and research of new drugs selectively acting on NMDARs for the pharmacotherapy of mental disorders.

\section{Translational Models of Neurotoxins Applicability}

Despite their high molecular specificity majority of neurotoxins can not cross blood-brain barrier that limits their potential clinical applicability in the amelioration of psychiatric diseases. Indeed, none of the described neurotoxins have been clinically tested so far, however, there are some observations that may indicate certain possibilities of their clinical application. Acyl polyamine toxin JSTX-3 or its derivatives may become new antiepileptic drugs in the future. This toxin was tested on human hippocampal slices taken surgically from patients with refractory medial temporal lobe epilepsy. The epileptiform activity induced by $\mathrm{Mg}^{2+-}$ free artificial cerebrospinal fluid and $\mathrm{N}$-methyl-D-aspartate were blocked by incubation with JSTX-3 indicating its antiepileptic effect (Salamoni et al., 2005). Also, a-Agatoxin-489 and its derivatives may be related to epilepsy treatment and may be candidates for new antiepileptic drugs with selective effect on excitatory synaptic transmission related to NMDA receptor-mediated excitatory postsynaptic currents. The action of agatoxin has been shown to be related to the antiepileptic mechanism of levetiracetam in granule cells in dentate gyrus in brain slice preparations from Wistar rats (Lee et al., 2009). As mentioned earlier, argiotoxins, agatoxins and neurotoxin JSTX-3 might become new non-ketamine NMDAR antagonists to tested in the treatment of depression as new antidepressants, while $\Gamma$-Ctenitoxin-Pn1a and its derivatives as NMDA receptor modulators may be tested in in the direction of drugs improving cognitive functions and as such, supporting the treatment of schizophrenia. Argiotoxins, agatoxins and neurotoxins JSTX-3 as an NMDAantagonist may be investigated in the context of a potential neuroprotective effect similar to that of the other NMDA$\mathrm{R}$ blocker dizocilpine (MK-801) observed with long-term administration in the rat hippocampus (Cigel et al., 2021).

Interestingly, targeted injections of botulinum neurotoxin A (BoNT/A) into the human frontalis and procerus muscles results in a considerable reduction of depressive symptoms, 40-50\% (Finzi \& Rosenthal, 2014). The use of this toxin is considered safe and it can potentially be applied as a supporting method in the pharmacological treatment of depression. Noteworthy, antidepressive effect of a single dose of BoNT/A administered to a patient with major depressive disorder may persist for 4 weeks or more (Hexsel et al., 2013; Magid et al., 2014). The mechanism behind this effect is unknown, yet evidence obtained from several methodologically sound clinical trials encourage the use of this method of pharmacotherapy.

The neuroprotective effects of these neurotoxins or their derivatives could be exploited in the development of new 
drugs for the treatment of stroke, neurodegenerative diseases and the related cognitive deficits.

\section{Spider Neurotoxins and NMDAR-Related Glutamate Transmission}

Up to 50000 spider species has been discovered on Earth. Although, all of them possess functional venomous glands, only of 1400 venoms have been described so far. A wide spectrum of natural neurotoxic molecules isolated from spider venoms can target, often strongly and selectively, various types of neuronal receptors and ion channels. For instance hanatoxin (HaTx1) from Grammostola spatulata acts as selective blocker of voltage-gated Kv 2.1 potassium channel (Chen et al., 2012) but w-agatoxin 1A from Agelenopsis aperta inhibits P/Q calcium channels exclusively (Nakanishi, 2016). Several polypeptides, polyamines and acylpolyamines may act as more or less selective, noncompetitive antagonists of NMDAR-related glutamatergic signaling both in insects and vertebrates (Table 1). Intriguingly, number of spider neurotoxins affect insect cellular targets exclusively and their effect on vertebrate neurons is very subtle or none. For instance, a toxin peptide $\omega / \kappa$ HXTV-Hv1a isolated from the venom of Australian Blue Mountains spider Hadronyche versuta blocks voltage gated calcium channels $\left(\mathrm{Ca}_{\mathrm{v}}\right)$ of the insect neurons with no effect on mammalian ion currents (King \& Hardy, 2013).

\section{Г-Ctenitoxin-Pn1a}

The venom produced by South American Phoneutria sp. armed spiders is considered a source of toxins that can modulate NMDAR physiology. The frequency of serious bites caused by aggressive Phoneutria nigriventer species is relatively high therefore accumulating studies investigate the chemical composition of its venom. Over 40 neurotoxic molecules were identified and isolated from the crude secretion of spider venomous glands (Peigneur et al., 2018).

$\Gamma$-Ctenitoxin-Pn1a (Г-CNTX-Pn 1 a) is a 81-aminoacid single-chain polypeptide with molecular mass of $5.17 \mathrm{kDa}$ isolated from the PhTx 4 fraction of the $P$. nigriventer venom (Fig. 1). Neurotoxin molecules are not able to cross blood-brain barrier (Oliveira et al., 2019). Intracerebroventicular injection of $\Gamma$-CNTX-Pn1a at dose $30 \mathrm{mg} /$ individual did not cause behavioural impairment in mice. However, administration of $1 \mathrm{mM} \Gamma$-CNTX-Pn1a reversibly but selectively inhibits the NMDARs ion current in cultured rat hippocampal neurons and decreases by two-thirds the receptor response. Both AMPA and kainic glutamate receptors are not affected by the toxin (Figueiredo et al., 2001). Similarly, Г-CNTX-Pn1a (100 nM) significantly reduces NMDARs activity in hippocampal slices stimulated via CA1 Schaffer collaterals (Silva et al., 2016). On the other hand, both peripheral (at dose 2.5-10 $\mathrm{mg} /$ paw, itraplantar) and systemic $(2.5 \mathrm{mg} / \mathrm{kg})$ injection of $\Gamma$-CNTX-Pn1 decreases the L-glutamate and PGE2-induced hyperalgesia in rats (Oliveira et al., 2019, Lauria et al. 2020). The mechanism of neurotoxin action

Table1 An outline characteristics of the most important spider neurotoxins with a proven affinity to NMDA receptors

\begin{tabular}{|c|c|c|c|c|c|c|}
\hline Neurotoxin name & & Species & $\begin{array}{l}\text { Molecular } \\
\text { mass (Da) }\end{array}$ & Structure & Effects & Reference \\
\hline Ctenitoxin- $\mathrm{Pb} 48$ & & $\begin{array}{l}\text { Phoneutria boliviensis } \\
\text { Phoneutria nigriventer }\end{array}$ & 1341.5 & Polypeptide & NMDAR antagonist & $\begin{array}{l}\text { Estrada-Gomez et al. } \\
2015\end{array}$ \\
\hline Ctenitoxin-Pb53 & & $\begin{array}{l}\text { Phoneutria boliviensis } \\
\text { Phoneutria nigriventer }\end{array}$ & 1265.6 & Polypeptide & NMDAR antagonist & $\begin{array}{l}\text { Estrada-Gomez et al. } \\
2015\end{array}$ \\
\hline$\Gamma$-Ctenitoxin-Pn1a & $\operatorname{PnT} \times 5(5-5)$ & Phoneutria nigriventer & 5170 & Polypeptide & $\begin{array}{l}\text { NMDAR antagonist } \\
(100 \mathrm{~nm})\end{array}$ & Silva et al., 2016 \\
\hline$\delta$-Ctenitoxin-Pn1a & $\operatorname{PnTx} 4(6-1)$ & Phoneutria nigriventer & 5838.8 & Polypeptide & $\begin{array}{l}\text { NMDAR antagonist } \\
(1 \mathrm{mM})\end{array}$ & Lauria et al., 2020 \\
\hline Parawixin 10 (Pwx10) & PbTx1.2.3 & Parawixia bistriata & 587.5 & Polyamine & $\begin{array}{l}\text { EAAT2 blocker (10 ng/ } \\
\text { ml) }\end{array}$ & Fachim et al., 2015 \\
\hline Argiotoxin636 & ArgTX-636 & Argiope lobata & 636.8 & Polyamine & NMDAR antagonist & Albensi et al., 2000 \\
\hline Argiotoxin659 & ArgTX-659 & $\begin{array}{l}\text { Argiope aurantia } \\
\text { Argiope lobata }\end{array}$ & 659.8 & Polyamine & $\begin{array}{l}(3 \mathrm{mM}) \\
\text { NMDAR antagonist } \\
(20 \mathrm{mM})\end{array}$ & Mueller et al., 1991 \\
\hline $\begin{array}{l}\alpha \text {-Agatoxin- } 489 \\
\text { Joro spider toxin }\end{array}$ & $\begin{array}{l}\text { AG } 489 \\
\text { JSTX-3 }\end{array}$ & $\begin{array}{l}\text { Agelenopsis aperta } \\
\text { Nephila clavata }\end{array}$ & $\begin{array}{l}489.7 \\
565.3\end{array}$ & $\begin{array}{l}\text { Polyamine } \\
\text { Polyamine }\end{array}$ & $\begin{array}{l}\text { NMDAR antagonist } \\
(20 \mathrm{mM}) \\
\text { NMDAR antagonist } \\
(20 \mathrm{mM})\end{array}$ & $\begin{array}{l}\text { Monge-Fuentes et al., } \\
2015 \\
\text { Mueller et al., } 1991\end{array}$ \\
\hline
\end{tabular}




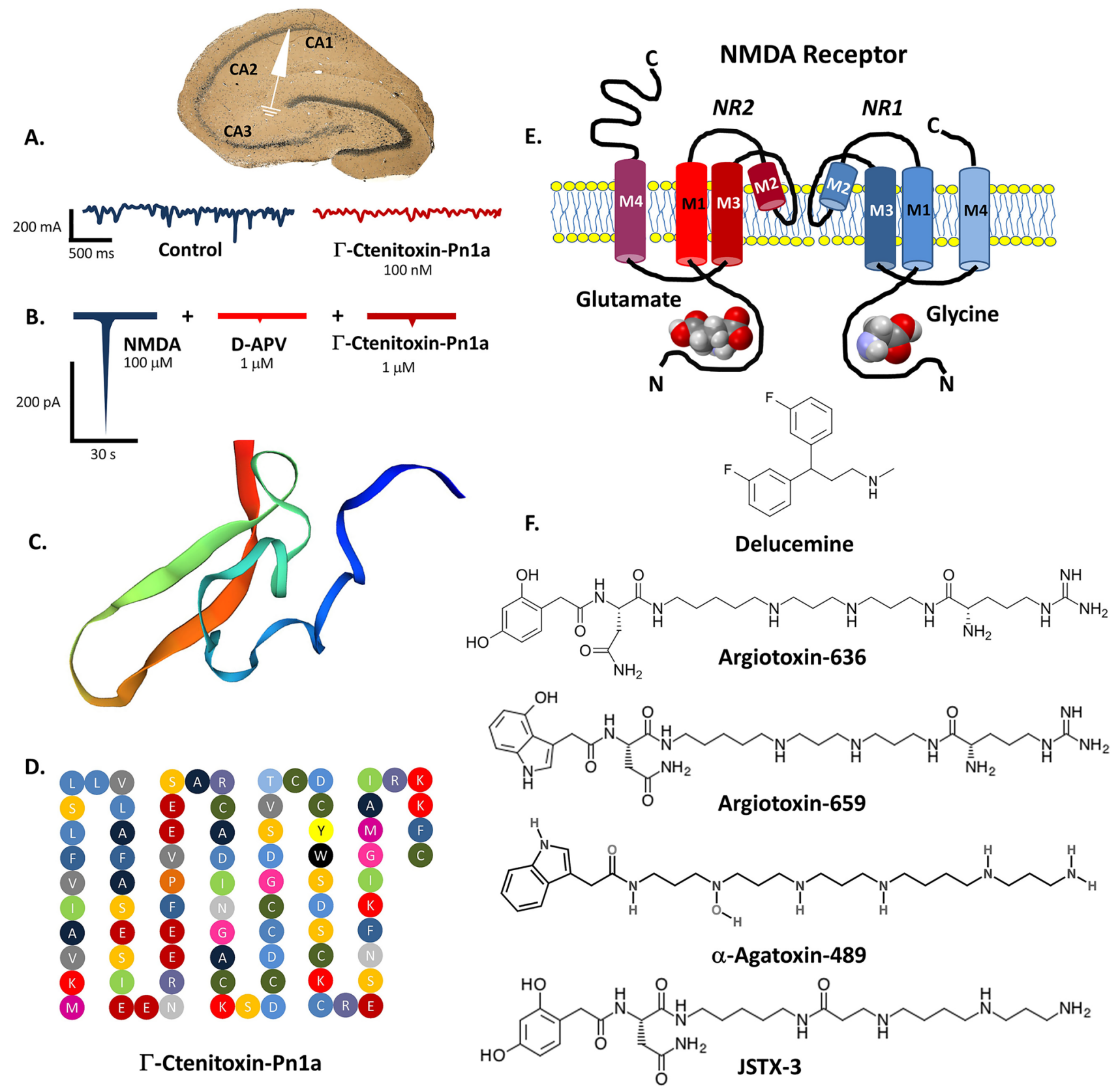

Fig.1 The whole-cell recording voltage-clamp of CA1 pyramidal neurons in hippocampal slices treated with $\Gamma$-Ctenitoxin-Pn1a (A). A decreased amplitude of NMDAR-mediated excitatory postsynaptic currents (EPSCs) is shown on the right (partly based on Silva et al. 2016, modified). Currents recorded from cultured rat hippocampal neurons (B). NMDA-evoked responses in the absence (control) and in the presence of $\Gamma$-Ctenitoxin-Pn1a or selective NMDA receptor

is not yet fully understood. Antinociceptive effects of $\Gamma$-CNTX-Pn 1 may be caused by local $\mathrm{Na}_{\mathrm{v}} 1.3$ and $\mathrm{Na}_{\mathrm{v}}$ 1.6 sodium channels blockade or/and inhibition of central NMDA-related signaling at the level of spinal dorsal horn neurons (Paiva et al., 2016). A distinct structural similarity $(63 \%$ of sequence homology) with $\delta$-Ctenitoxin-Pn $1 \mathrm{a}$
antagonist-D-2-amino-5-phosphonovalerate; D-APV (data taken from Figueiredo et al., 2001, design modified). 3-D conformation of $\Gamma$-Ctenitoxin-Pn1a molecule $(\mathbf{C})$ and its linear aminoacid sequence (D).The scheme of NMDA receptor molecule depicting all transmembrane domains of its two subunits GLUN1 and GLUN2 and ligand binding sites (E). Chemical structures of spider venom-derived polyamine NMDA receptor antagonists and antidepressant delucemine $(\mathbf{F})$ may probably determine the neurophysiological properties of $\Gamma$-CNTX-Pn1. Interestingly, $\Gamma$-CNTX-Pn1 at picomolar concentrations exhibits neuroprotective effect on mouse corticostriatal neurons after glutamate-induced excitotoxicity and amyloid b-related cellular injury (Silva et al., 2016). Furthermore, in the mouse model of Huntington 
disease, $\Gamma$-CNTX-Pn1 (at dose $1 \mathrm{nM}$ ) promotes survival of BACHD neurons injured with toxic concentrations of glutamate (Silva et al., 2016). Novel neurotoxin ctenitoxin- $\mathrm{Pb} 53$, isolated recently from Phoneutria boliviensis venom is also considered as NMDARs modulator due to its high conformational homology with $\Gamma$-Ctenitoxin-Pn1a. Another factor identified in this venom, ctenitoxin-Pb48 structurally analogous with w-Ctenitoxin-Pn1a, may also potentially affect glutamate signaling (Estrada-Gomez 2015).

\section{Argiotoxins}

Argiotoxin-636 (ArgTX-636, argiopine), $\mathrm{C}_{29} \mathrm{H}_{52} \mathrm{~N}_{10} \mathrm{O}_{6}$ is an acypolyamine isolated from the venom of orb-weaver spiders Argiope lobata and Argiope aurantia (Fig. 1). Acting as very potent antagonist of NMDAR signalling, ArgTX-636 blocks receptor ion channel at low concentrations. ArgTX-636 at dose $3 \mathrm{mM}$ acts as a NMDAR open channel blocker and it can halve the NMDARs activity of the rat cortical neurons in voltage-dependent manner. The similar effect was observed in cultured cerebellar granule cells and hippocampal neurons. Moreover, even lower concentrations of the neurotoxin are able to block tritiumlabeled dizocilpine binding to the rat brain neuronal cell membranes. This effect is independent from alterations of glycine, glutamate and spermidine concentrations but a distinct affinity of ArgTX-636 to the $\mathrm{Mg}^{2+}$ binding site within NMDAR channel pore is suggested (Albensi et al., 2000). Mutations of a pore forming asparagine residue located in the NMDARs transmembrane M2 domain abolishes the ArgTX-636 action but sequence differences in the $\mathrm{M} 2$ region of both GluN2A and GluN2C subunits are not connected with the receptor sensitivity to ArgTX-636. Interestingly, ArgTX-636 has a very selective affinity for the GluN1/2A and GluN1/2B structural subtypes. This makes ArgTX-636 a valuable and precise molecular tool for the neuropharmacological study of NMDAR structure and function both in animal and in vitro models. Importantly, an inhibition of NMDAR transmission with ArgTX636 as well as with other alkylamine toxins does not affect hippocampal LTP generation thus cognitive processes are not impaired (Albensi et al., 2000). Noteworthy, the structure of novel, preclinically studied selective serotonin reuptake inhibitor (SSRI) and NMDAR antagonist-delucemine (NPS-1506, Fig. 1.) is based on the ArgTX-636 molecule (Monge-Fuentes et al., 2015). Argiotoxin-659 (ArgTX-659, argiopinine), $\mathrm{C}_{31} \mathrm{H}_{53} \mathrm{~N}_{11} \mathrm{O}_{5}$ is the next very potent NMDAR antagonist with analogous mode of action to ArgTX-636. Postsynaptic excitatory potentials of the rat hippocampal neurons are non-competitively silenced by both aforementioned neurotoxins at almost the same doses (20 and $24 \mathrm{mM}$ respectively) (Mueller et al., 1991).

\section{a-Agatoxin-489 (AG 489)}

Agatoxins are neuroactive polyamines isolated from the venom of desert grass spider Agelenopsis aperta. Three structural subclasses of agatoxins (a, $\mathrm{m}$ and $\mathrm{w}$ ) grouping at least 16 isoforms are currently known. Majority of them such as aforementioned w-agatoxin $1 \mathrm{~A}$ exhibit potent and very selective affinity to neuronal ion channels. $\alpha$-Agatoxin-489, ( $N$-(20-Amino-4-hydroxy-4,8,12,17-tetraazaicosan-1-yl)-2(9H-purin-3-yl)acetamide, $\mathrm{C}_{26} \mathrm{H}_{47} \mathrm{~N}_{7} \mathrm{O}_{2}$, Fig. 1) is the most potent non-competitive blocker of NMDAR-dependent calcium current in rat cerebellar granule cells and hippocampal neurons (Kiskin et al., 1992), however other a-agatoxins also exhibit analogous inhibitory activity. Noteworthy, AG489 unlike ArgTX-636 enhances $\left[{ }^{3} \mathrm{H}\right]$-dizocilpine binding to rat brain neuronal membranes at low concentrations only via stimulation of NMDARs polyamine site (Monge-Fuentes et al., 2015).

\section{Joro Spider Toxin (JSTX-3)}

Studies on neurotoxin JSTX-3, $\mathrm{C}_{27} \mathrm{H}_{47} \mathrm{~N}_{7} \mathrm{O}_{6}$ (Fig. 1) isolated from the venom of Joro spider Nephila clavata have provided unconclusive results. On the one hand, it is considered an inhibitor of EPSPs in rat hippocampal CA1 neurons at dose $20 \mathrm{mM}$ (Mueller et al., 1991) but other reports suggest that only minor part of ion current blockade by JSTX-3 is an effect of NMDARs inhibition (Sahara et al., 1991) or neurotoxin activity is rather weak, as in case of rat spinal neurons (Jones \& Lodge, 1991).

\section{Parawixin 10 (Pwx10)}

Parawixin 10 (Pwx10, PbTx1.2.3) a polyamine isolated from the venom of South American species Parawixia bistriata modulates glutamatergic signaling indirectly via stimulation of glutamate transporter 2 (EAAT2) activity. Studies on rat cortical synaptosomes in vitro revealed an increase of neurotransmitter reuptake after treatment with Pwx10 at dose $10 \mathrm{ng} / \mathrm{ml}$ without disturbing of EAAT2 affinity to sodium ions. The precise mechanism of Pwx10 action is so far unknown, however it should be suggested that it may potentially reduce excitotoxic injuries without blocking NMDARs action (Fachim et al., 2015). 


\section{Concluding Remarks}

The NMDA receptor modulators are currently an important subject of widespread neuropharmacological research. Spider polypeptide and arylkylamine neurotoxins act as potent and selective NMDAR antagonists that do not disturb central cognitive mechanisms related to hippocampal glutamate transmission, LTP generation and synaptic plasticity. It is possible that such promising neuroactive peptides can be clinically applicable in a wide spectrum of neuropsychiatric disorders, including epilepsy, neurotrauma and ischemic injuries. Several contemporary research suggest an intriguing possibility of spider-venom derived drug designing. These novel medications can potentially be helpful in the treatment of stroke and neurodenerative diseases. For instance, neurotoxin Hila isolated from the Australian species Hadronyche infensa exposes distinct neuroprotective properties and significantly reduces post ischemic brain dysfunctions in animal model (Chassagnon et al., 2017). Unfortunately, number of these macromolecular compounds particularly Phoneutria sp. neurotoxins do not cross blood-brain barrier and their efficient delivery to the brain is therefore extremely difficult. Nevertheless, many of them may be treated as structural scaffolds or model molecules in the development of novel, potentially effective and more safe pharmacological strategies.

Author contributions AP, MK: conceptualization, resources, writing—original draft.

Funding This work was supported by the Medical University of Silesia grant for Department of Histology No; PCN-1-011/K/0/O.

\section{Declarations}

Conflict of Interest Author declare no conflict of interest.

Open Access This article is licensed under a Creative Commons Attribution 4.0 International License, which permits use, sharing, adaptation, distribution and reproduction in any medium or format, as long as you give appropriate credit to the original author(s) and the source, provide a link to the Creative Commons licence, and indicate if changes were made. The images or other third party material in this article are included in the article's Creative Commons licence, unless indicated otherwise in a credit line to the material. If material is not included in the article's Creative Commons licence and your intended use is not permitted by statutory regulation or exceeds the permitted use, you will need to obtain permission directly from the copyright holder. To view a copy of this licence, visit http://creativecommons.org/licenses/by/4.0/.

\section{References}

Albensi, B. C., Alasti, N., \& Mueller, A. L. (2000). Long-term potentiation in the presence of NMDA receptor antagonist arylalkylamine spider toxins. Journal of Neuroscience Research, 62(2), 177-185. https://doi.org/10.1002/1097-4547(20001015)62:2

Andrade, C. (2017). Memantine as an Augmentation Treatment for Schizophrenia: Limitations of Meta-Analysis for Evidence-Based Evaluation of Research. Journal of Clinical Psychiatry, 78(9), e1307-e1309. https://doi.org/10.4088/JCP.17f11998

Chang, C. H., Lane, H. Y., Tseng, P. T., Chen, S. J., Liu, C. Y., \& Lin, C. H. (2019). Effect of N-methyl-D-aspartate-receptor-enhancing agents on cognition in patients with schizophrenia: A systematic review and meta-analysis of double-blind randomised controlled trials. Journal of Psychopharmacology, 33(4), 436-448. https:// doi.org/10.1177/0269881118822157

Chassagnon, I. R., McCarthy, C. A., Chin, Y. K., Pineda, S. S., Keramidas, A., Mobli, M., et al. (2017). Potent neuroprotection after stroke afforded by a double-knot spider-venom peptide that inhibits acid-sensing ion channel 1a. Proceedings of the National Academy of Sciences USA, 114(14), 3750-3755. https://doi.org/10.1073/pnas.1614728114

Chen, R., Robinson, A., \& Chung, S. H. (2012). Binding of hanatoxin to the voltage sensor of Kv2.1. Toxins, 4(12), 1552-1564. https://doi.org/10.3390/toxins4121552

Cigel, A., Sayin, O., Gurgen, S. G., \& Sonmez, A. (2021). Long term neuroprotective effects of acute single dose MK-801treatment against traumatic brain injury in immature rats. Neuropeptides, 88, 102161. https://doi.org/10.1016/j.npep.2021.102161

Diazgranados, N., Ibrahim, L., Brutsche, N. E., Newberg, A., Kronstein, P., Khalife, S., et al. (2010). A randomized add-on trial of an N-methyl-D-aspartate antagonist in treatment-resistant bipolar depression. Archieves of General Psychiatry, 67(8), 793-802. https://doi.org/10.1001/archgenpsychiatry.2010.90

Dubois, C. J., \& Liu, S. J. (2021). GluN2D NMDA receptors gate fear extinction learning and interneuron plasticity. Frontiers in Synaptic Neuroscience, 13, 681068. https://doi.org/10.3389/ fnsyn.2021.681068

Fachim, H. A., Mortari, M. R., Gobbo-Netto, L., \& Dos Santos, W. F. (2015). Neuroprotective activity of parawixin 10, a compound isolated from Parawixia bistriata spider venom (Araneidae: Araneae) in rats undergoing intrahippocampal NMDA microinjection. Pharmacognosy Magazine, 11(43), 579-585.

Figueiredo, S. G., de Lima, M. E., Nascimento Cordeiro, M., Diniz, C. R., Patten, D., Halliwell, R. F., et al. (2001). Purification and amino acid sequence of a highly insecticidal toxin from the venom of the brazilian spider Phoneutria nigriventer which inhibits NMDA-evoked currents in rat hippocampal neurones. Toxicon, 39(2-3), 309-317. https://doi.org/10.1016/s00410101(00)00129-x

Finzi, E., \& Rosenthal, N. E. (2014). Treatment of depression with on a botulinum toxin A: A randomized, double-blind, placebo controlled trial. Journal of Psychiatric Research, 52, 1-6.

Hexsel, D., Brum, C., Siega, C., Schilling-Souza, J., Dal'Forno, T., Heckmann, M., \& Rodrigues, T. C. (2013). Evaluation of self-esteem and depression symptoms in depressed and nondepressed subjects treated with on a botulinum toxin A for glabellar lines. Dermatologic Surgery, 39, 1088-1096. https://doi.org/ $10.1111 /$ dsu. 12175

Jones, M. G., \& Lodge, D. (1991). Comparison of some arthropod toxins and toxin fragments as antagonists of excitatory amino acid-induced excitation of rat spinal neurones. European Journal of Pharmacology, 204(2), 203-209. https://doi.org/10.1016/ 0014-2999(91)90706-v 
King, G. F., \& Hardy, M. C. (2013). Spider-venom peptides: Structure, pharmacology, and potential for control of insect pests. Annual Review of Entomology, 58, 475-496. https://doi.org/10. 1146/annurev-ento-120811-153650

Kishimoto, T., Chawla, J. M., Hagi, K., Zarate, C. A., Kane, J. M., Bauer, M., \& Correll, C. U. (2016). Single-dose infusion ketamine and non-ketamine N-methyl-d-aspartate receptor antagonists for unipolar and bipolar depression: A meta-analysis of efficacy, safety and time trajectories. Psychological Medicine, 46(7), 1459-1472. https://doi.org/10.1017/S0033291716000064

Kiskin, N. I., Chizhmakov, I. V., Tsyndrenko, A. Y., Mueller, A. L., Jackson, H., \& Krishtal, O. A. (1992). A highly potent and selective $\mathrm{N}$-methyl-D-aspartate receptor antagonist from the venom of the Agelenopsis aperta spider. Neuroscience, 51(1), 11-18. https://doi.org/10.1016/0306-4522(92)90465-e

Krzystanek, M., \& Pałasz, A. (2019). NMDA receptor model of antipsychotic drug-induced hypofrontality. International Journal of Molecular Sciences, 20(6), 1442. https://doi.org/10.3390/ ijms20061442

Lee, C. Y., Chen, C. C., \& Liou, H. H. (2009). Levetiracetam inhibits glutamate transmission through presynaptic P/Q-type calcium channels on the granule cells of the dentate gyrus. British Journal of Pharmacology, 158(7), 1753-1762. https://doi.org/10.1111/j. 1476-5381.2009.00463.x

Magid, M., Reichenberg, J. S., Poth, P. E., Robertson, H. T., LaViolette, A. K., Kruger, T. H., \& Wollmer, M. A. (2014). Treatment of major depressive disorder using botulinum toxin A: A 24-week randomized, double-blind, placebo-controlled study. Journal of Clinical Psychiatry, 75, 837-844. https://doi.org/10.4088/JCP. $13 \mathrm{~m} 08845$

Marchi, M., Galli, G., Magarini, F. M., Mattei, G., \& Galeazzi, G. M. (2021). Sarcosine as an add-on treatment to antipsychotic medication for people with schizophrenia: A systematic review and meta-analysis of randomized controlled trials. Expert Opinion in Drug Metabolism and Toxicology, 17(4), 483-493. https://doi.org/ 10.1080/17425255.2021.1885648

Monge-Fuentes, V., Gomes, F. M., Campos, G. A., Silva, Jd., Biolchi, A. M., Dos Anjos, L. C., et al. (2015). Neuroactive compounds obtained from arthropod venoms as new therapeutic platforms for the treatment of neurological disorders. The Journal of Venomous Animals and Toxins including Tropical Diseases, 21(31), 31. https://doi.org/10.1186/s40409-015-0031-

Mueller, A. L., Albensi, B. C., Ganong, A. H., Reynolds, L. S., \& Jackson, H. (1991). Arylamine spider toxins antagonize NMDA receptor-mediated synaptic transmission in rat hippocampal slices. Synapse (new York, N. Y.), 9(4), 244-250. https://doi.org/10.1002/ syn. 890090403

Nakanishi, S. (2016). A spider toxin, omega-agatoxin IV A, binds to fixed as well as living tissues: Cytochemical visualization of P/Qtype calcium channels. Microscopy, 65(4), 337-340. https://doi. org/10.1093/jmicro/dfw013
Oliveira, C.F.B., Alves, D.P., Emerich, B.L., de Figueiredo, S.G., Cordeiro, M.D.N., Borges, M.H.et al. (2019). Antinociceptive effect of PnTx4(5-5), a peptide from Phoneutria nigriventer spider venom, in rat models and the involvement of glutamatergic system.The Journal of Venomous Animals and Toxins Including Tropical Diseases, 25: e20190022

Paiva, A. L., Matavel, A., Peigneur, S., Cordeiro, M. N., Tytgat, J., Diniz, M. R., \& de Lima, M. E. (2016). Differential effects of the recombinant toxin PnTx4(5-5) from the spider Phoneutria nigriventer on mammalian and insect sodium channels. Biochimie, 121, 326-335. https://doi.org/10.1016/j.biochi.2015.12.019

Peigneur, S., de Lima, M. E., \& Tytgat, J. (2018). Phoneutria nigriventer venom: A pharmacological treasure. Toxicon, 151, 96-110. https://doi.org/10.1016/j.toxicon.2018.07.008

Price, R. B., Iosifescu, D. V., Murrough, J. W., Chang, L. C., Al Jurdi, R. K., Iqbal, S. Z., et al. (2014). Effects of ketamine on explicit and implicit suicidal cognition: A randomized controlled trial in treatment-resistant depression. Depression and Anxiety, 31(4), 335-343. https://doi.org/10.1002/da.22253

Regan, M. C., Romero-Hernandez, A., \& Furukawa, H. A. (2015). structural biology perspective on NMDA receptor pharmacology and function. Current Opinion in Structural Biology, 33, 68-75. https://doi.org/10.1016/j.sbi.2015.07.012

Sahara, Y., Robinson, H. P., Miwa, A., \& Kawai, N. A. (1991). voltageclamp study of the effects of Joro spider toxin and zinc on excitatory synaptic transmission in CA1 pyramidal cells of the guinea pig hippocampal slice. Neuroscience Research, 10(3), 200-210. https://doi.org/10.1016/0168-0102(91)90057-6

Salamoni, S. D., da Costa, J. C., Palma, M. S., Konno, K., Nihei, K., Azambuja, N. A., Neto, E. P., Venturin, G. T., Tavares, A. A., de Abreu, D. S., \& Breda, R. V. (2005). The antiepileptic activity of JSTX-3 is mediated by N-methyl-D-aspartate receptors in human hippocampal neurons. NeuroReport, 16(16), 1869-1873. https:// doi.org/10.1097/01.wnr.0000185012.98821.2b

Silva, F. R., Batista, E. M., Gomez, M. V., Kushmerick, C., Da Silva, J. F., Cordeiro, M. N., et al. (2016). The Phoneutria nigriventer spider toxin, PnTx4-5-5, promotes neuronal survival by blocking NMDA receptors. Toxicon, 15(112), 16-21. https://doi.org/10. 1016/j.toxicon.2016.01.056

Zarate, C. A., Jr., Brutsche, N. E., Ibrahim, L., Franco-Chaves, J., Diazgranados, N., Cravchik, A., et al. (2012). Replication of ketamine's antidepressant efficacy in bipolar depression: A randomized controlled add-on trial. Biological Psychiatry, 71(11), 939-946. https://doi.org/10.1016/j.biopsych.2011.12.010

Publisher's Note Springer Nature remains neutral with regard to jurisdictional claims in published maps and institutional affiliations. 